\title{
Negociación colectiva en Colombia: una visión cruzada entre el sector público y el sector privado
}

\author{
Collective Bargaining in Colombia: Cross-Sight between the Public Sector \\ and the Private Sector \\ Negociação coletiva na Colômbia: uma visão cruzada entre o setor público \\ e o setor privado
}

\section{Pierre-Henri Cialti ${ }^{*}$}

FECHA DE RECEPCIÓN: 31 DE JULIO DE 2015. FECHA DE ACEPTACIÓN: 20 DE OCTUBRE DE 2015

Doi: dx.doi.org/10.12804/esj 18.01.2016.06

Para citar este artículo: Cialti, P. H. (2016). Negociación colectiva en Colombia: una visión cruzada entre el sector público y el sector privado. Estudios Socio-Jurídicos, 18(1), 169-203. Doi: dx.doi.org/10.12804/esj18.01.2016.06

\section{RESUMEN}

La tasa de cobertura convencional en Colombia presenta un índice bajo en extremo, que contrasta con el reconocimiento constitucional del derecho a la negociación colectiva. Tras poner de relieve el papel del legislador en cuanto al desarrollo del derecho a la negociación colectiva constitucionalmente reconocido, este trabajo centra su propósito en dos aspectos fundamentales: la determinación de los actores de la negociación y la eficacia del producto negociado. En este marco, un estudio cruzado de los regímenes jurídicos de la negociación colectiva de los empleados públicos y de aquella en el sector privado resulta pertinente, ya que surge una paradoja. Mientras ambos dispositivos otorgan a cualquier sindicato legalmente constituido la facultad de negociar, las condiciones de aplicación del producto negociado varían. Esta situación conduce a proyectarse hacia su convergencia desde dos elementos clave del sistema de negociación colectiva para mejorar la tasa de cobertura convencional: el refuerzo de la representatividad de los negociadores y la ampliación de los efectos del producto negociado.

Palabras clave: negociación colectiva, convención colectiva, representatividad, legitimación, eficacia.

* Doctor en Derecho. Docente investigador de la Corporación Universitaria del Caribe (Cecar), Sincelejo (Colombia). Artículo de investigación que forma parte del proyecto de investigación "Hacia el fortalecimiento de la negociación colectiva de los empleados públicos en Colombia", integrado al Grupo de investigación sociojurídico Giscer, del Centro de Investigaciones de la Corporación Universitaria del Caribe (Cecar). Correo electrónico: pierrecialti@gmail.com 


\section{ABSTRACT}

Conventional coverage rate in Colombia has an extremely low contrasting with the constitutional recognition of the right to collective bargaining. After a brief analysis of the right to collective bargaining from a constitutional perspective, this paper aims to focus on two central purposes that are directly linked to the implementation of the collective agreement: negotiators and effectiveness of the convention. In this context, a crossover study of the legal regimes of the collective bargaining for public employees and collective bargaining in the private sector is relevant for several reasons. Indeed, while both devices assign to any trade-union the power to negotiate, the application conditions of the negotiated product vary substantially. This, therefore, leads to project toward convergence of both legal systems on two main aspects: to reinforce the legitimacy of the negotiators and to extend the effects of the negotiated product.

Keywords: collective bargaining, collective agreement, representativeness, legitimation, effectiveness.

\section{RESUMO}

A taxa de cobertura convencional na Colômbia apresenta um nível extremadamente baixo que contrasta com o reconhecimento constitucional do direito à negociação coletiva. Depois de destacar o papel do legislador em quanto ao desenvolvimento do direito à negociação coletiva constitucionalmente reconhecido, este trabalho centra o seu propósito sobre dois aspectos fundamentais do desenvolvimento deste direito: a determinação dos atores da negociação e da eficácia do produto negociado. Neste marco, um estudo cruzado dos regimes jurídicos da negociação coletiva dos empregados públicos e da negociação coletiva no setor privado resulta pertinente, devido que surge disso um paradoxo. Em efeito, enquanto ambos os dispositivos outorgam a qualquer sindicato legalmente constituído a faculdade de negociar, as condições de aplicação do produto negociado variam substancialmente. Esta situação conduz, portanto, a se projetar à convergência de ambos os dispositivos sobre dois elementos chave do sistema de negociação coletiva para melhorar a taxa de cobertura convencional: o fortalecimento da representatividade dos negociadores e a ampliação dos efeitos do produto negociado.

Palavras- chave: Negociação coletiva, Convenção coletiva, representatividade, legitimação, eficácia. 


\section{Introducción}

En 2012, la Población Económicamente Activa (PEA) alcanzaba en Colombia la cifra de 23.003.356 personas (Ministerio de Trabajo, 2012). De ellas, 80.784 integran el ámbito de aplicación de una convención colectiva (Escuela Nacional Sindical, 2013), es decir, que Colombia tiene una tasa de cobertura convencional de 0,35\%. Sin embargo, la Constitución Política colombiana de 1991 (en adelante, CPC) establece en su Artículo 55 que "se garantiza el derecho de negociación colectiva para regular las relaciones laborales con las excepciones que señale la ley. Es deber del Estado promover la concertación y los demás medios para la solución pacífica de los conflictos de trabajo".

Sin lugar a dudas, el precepto constitucional forma parte de una retórica que no se plasma en la realidad social. El objetivo de este trabajo radica en proponer una visión cruzada de los modelos legales de negociación colectiva de los empleados públicos y de los trabajadores del sector privado, que permitirá subrayar la existencia de una paradoja respecto a la combinación de dos aspectos estrechamente vinculados con la problemática de la tasa de cobertura convencional: la determinación de las partes a la negociación y la atribución de un tipo de eficacia a la convención. Dicha paradoja resulta aún más llamativa, si se tiene en cuenta el papel atribuido al legislador por la Constitución de 1991 en el fomento del derecho a la negociación colectiva.

El análisis se hará desde el punto de vista de la dogmática jurídica, de lo normativo o deontológico, para reflexionar sobre el deber ser. Es cierto que para ser completo, el diagnóstico del modelo de sistema de negociación colectiva ha de abordar otra perspectiva. Así, desde el punto de vista sociojurídico, se ha afirmado que "las inconsistencias o los elementos negativos están esencialmente relacionados con la intolerancia social y no en la normatividad laboral vigente en Colombia" (Ostau de Lafont de León, 2011, p. 577). No obstante, el análisis jurídico formal del modelo de negociación colectiva demostrará que el marco legal y reglamentario del derecho a la negociación colectiva neutraliza y obstaculiza su adecuado desarrollo.

Para lograr el objetivo, es ineludible, en un primer momento, hacer un breve análisis del marco constitucional colombiano para resaltar el papel conferido a la ley en cuanto al desarrollo del sistema de negociación colectiva. En segundo lugar, trataremos el Derecho positivo, mediante el 
estudio del Decreto 160/2014, relativo a la negociación colectiva de los empleados públicos, así como de las disposiciones del Código Sustantivo del Trabajo (en adelante, CST) y del Decreto 87/2014, referentes a la negociación colectiva en el sector privado. Por último, adoptaremos una visión distinta frente al Derecho positivo abordado y formularemos proposiciones para contrarrestar las carencias de los dispositivos vigentes y favorecer el aumento de la tasa de cobertura convencional.

\section{El papel del legislador en materia de negociación colectiva en la Constitución de 1991}

El análisis del Artículo 55 CPC pasa por un estudio de la jurisprudencia de la Corte Constitucional. Dos aspectos importantes han de ser destacados de inmediato. Por una parte, no se trata de un derecho absoluto ${ }^{1} \mathrm{y}$, por otra, no se puede considerar como derecho fundamental, ubicado dentro de los derechos sociales, económicos y culturales (Corte Constitucional, 1995). ${ }^{2}$

Ahora bien, ¿el precepto constitucional tiene aplicación directa o necesita un desarrollo legal? El precepto constitucional remite a la ley la previsión de excepciones a su desarrollo, pero "garantiza" el derecho a la negociación colectiva. Una perspectiva comparada con el Derecho español resulta pertinente. Se han elaborado tres teorías respecto a la eficacia directa o no del precepto constitucional (Goerlich y García Rubio, 2006). La mayoría de la doctrina y la jurisprudencia se inclinaron por atribuir eficacia directa al precepto constitucional, lo que permite afirmar que el derecho a la negociación colectiva tiene fundamento constitucional y no precisa desarrollo legal para ser llevado a cabo. En línea con las palabras de la doctrina más autorizada, solo se garantiza lo que previamente se reconoce (Sala Franco, 1990). En este marco, incumbe a la ley establecer un dispositivo que ga-

1 La Corte afirma: "[...] ninguno de los derechos en mención -asociación sindical y negociación colectiva - tienen carácter absoluto en cuanto pueden ser limitados por la Ley [...] tales limitaciones deben ser razonadas y proporcionadas [...] justificadas en cuanto busquen proteger bienes constitucionalmente relevantes con la prevalencia del interés general" (Corte Constitucional, 2008a); asimismo, puede verse Corte Constitucional (2007).

2 Conviene apuntar que, cuando la vulneración del derecho de negociación colectiva afecta al derecho de libertad sindical o al derecho al trabajo, se aplica el dispositivo relativo a los derechos fundamentales. 
rantice este derecho, que tiene fundamento constitucional, pero presenta una configuración legal, pues atañe al legislador definir un dispositivo que lo garantice y respete su contenido esencial (Valdés Dal-Ré, 1990).

Colombia está en una situación muy similar. La configuración del derecho a la negociación corresponde al legislador, que puede señalar limitaciones justificadas por la protección de otros derechos constitucionales, mas, como lo subrayó la Corte Constitucional (2007; 2008b), la intervención legal tiene límites. ¿Cuáles son estos límites? $\mathrm{O}$, dicho de otro modo, ¿cuáles son los rasgos fundamentales del derecho a la negociación colectiva?, ¿cuál es su contenido esencial, según la terminología española? Frente al silencio del Artículo 55 al respecto, la Corte Constitucional (2008b) recurrió al Convenio 154 de la $\mathrm{OIT}^{3}$ y afirmó que la negociación tiene como objetivo fundamental "la justicia social" que pasa por mecanismos de "concertación", por el de fomento de la "tranquilidad social", "la defensa de los intereses comunes entre las partes" y el establecimiento de "garantías para que los representantes de las partes sean oídos" (p. 38). ${ }^{4}$

Conviene apuntar la lamentable ausencia de referencia a los titulares del derecho a la negociación colectiva en el precepto constitucional. La jurisprudencia constitucional ${ }^{5}$ insiste en el "acuerdo de voluntades" y la "esfera de libertad en cabeza de patronos y los trabajadores" (Guerrero, 2011, p. 440) y parece atribuir una doble titularidad, al reconocer este derecho tanto a la parte patronal como a la parte trabajadora. ${ }^{6}$

3 En virtud del Artículo 53 CPC, los convenios internacionales ratificados forman parte de la legislación interna, por lo que los tratados de los OIT integran el bloque de constitucionalidad. Para profundizar, pueden verse Molina (2005), Segrera Ayala y Torres Marenco (2005).

4 Esta Sentencia retoma la posición enunciada en la Sentencia C-1234 de 2005: "Sobre el concepto de 'negociación colectiva', contenido en el artículo $2^{\circ}$ del Convenio 154 de la OIT, la Corte ha señalado que esta expresión 'negociación colectiva', resulta ajustada a la Constitución, pues se enmarca en los siguientes objetivos : (i) busca lograr una concertación voluntaria y libre de las condiciones de trabajo; (ii) para ello, se hace necesario un diálogo que afiance el clima de tranquilidad social; (iii) el propósito de la negociación es la defensa de los intereses comunes entre las partes del conflicto económico laboral; y (iv) debe haber garantías para que los representantes de las partes sean oídos. Todos estos objetivos conducen al afianzamiento de la justicia social en las relaciones entre trabajadores y empleadores" (Corte Constitucional, 2005, pp. 38-39).

5 Los jueces afirman que "la negociación colectiva constituye un procedimiento que concreta y fortalece el acuerdo de voluntades [...]. Por consiguiente, la negociación colectiva libre y voluntaria se presenta en el ámbito constitucional como el derecho regulador de una esfera de libertad en cabeza de patronos y los trabajadores, que goza de amplio sustento y garantía constitucional" (Corte Constitucional, 2008b, p. 38). Asimismo, puede verse Corte Constitucional (1994).

6 En la misma línea, la Corte señala que "en el ámbito del derecho de negociación colecti- 
La aceptación de esta doble titularidad, así como la idea según la cual la negociación colectiva, "es uno de los medios más importantes para fijar las bases fundamentales del trabajo" y un "derecho regulador" (Corte Constitucional, 2008b, p. 38) implica que la actuación de la ley garantice un espacio vital a la negociación colectiva. Dicho de otro modo, el desarrollo legal ha de permitir a la negociación colectiva cumplir su función de fijación de las bases del trabajo y de regular las relaciones de trabajo y no puede reprimir u obstaculizar la negociación colectiva, sino, al contrario, debe fomentarla y promover su uso como mecanismo de definición de las condiciones de trabajo. Así, el derecho a la negociación colectiva reconocido a los empleadores y trabajadores se erige como un límite a la intervención del Estado en materia de fijación de las condiciones de trabajo. Encontramos esta misma idea en la Sentencia C-161/00, según la cual "el Estado no sólo debe garantizar el libre ejercicio de este derecho sino que debe promover la concertación y los demás medios para la solución pacífica de los conflictos colectivos de trabajo"?

Para rematar esta concepción, es preciso enunciar el Artículo 1 CPC, que configura a Colombia como "Estado social de Derecho", lo que implica un reparto del poder con los interlocutores sociales y su integración en los procesos de decisión, así como la inmersión del principio democrático en todos los ámbitos de la sociedad. El Artículo 2 enuncia los fines del Estado, entre los cuales figura "garantizar la efectividad de los principios, derechos y deberes consagrados en la Constitución" y "facilitar la participación de todos en las decisiones que los afectan y en la vida económica, política, administrativa y cultural de la Nación" ${ }^{8}$ El Artículo 103, literal 2, establece:

va, actúan como sujetos por excelencia los trabajadores y los empleadores, con claros y recíprocos derechos" (Corte Constitucional, 1992).

7 En la misma Sentencia se expresa: “[...] para la Corte, la promoción de la negociación colectiva tiene un sustento constitucional en el Preámbulo y el Artículo 2 de la Constitución que consagra el deber del Estado de promover y facilitar la participación de todos en las decisiones que los afectan, mandato que tiene que ver directamente con las funciones que cumple la negociación colectiva y que tienen que ver con la participación activa y decidida de los sujetos de la relación laboral, en la búsqueda de soluciones a los conflictos económicos que surgen de ella" (Corte Constitucional, 2000a, p.13).

8 "[...] para la Corte es claro que el impulso de la negociación colectiva en la legislación colombiana también tiene sustento en el preámbulo y en el Artículo $2^{\circ}$ de la Constitución, según los cuales el Estado debe promover y facilitar la participación de todos en las decisiones que los afectan" (Corte Constitucional, 2000a, p. 13). 
[...] el Estado contribuirá a la organización, promoción y capacitación de las asociaciones profesionales, cívicas, sindicales, comunitarias, juveniles, benéficas o de utilidad común no gubernamentales, sin detrimento de su autonomía con el objeto de que constituyan mecanismos democráticos de representación en las diferentes instancias de participación, concertación, control y vigilancia de la gestión pública que se establezcan.

En la misma línea, varios tratados bilaterales firmados por Colombia inciden en el necesario desarrollo del derecho a la negociación colectiva. A modo de ejemplo, podemos citar el Tratado de Libre Comercio con Estados Unidos que, en su parte laboral, se refiere al "reconocimiento efectivo del derecho de negociación colectiva" (República de Colombia y Estados Unidos de América, 2006).

A continuación abordaremos el marco legal y reglamentario que desarrolla el mandato constitucional.

La negociación colectiva en el sector privado o para los trabajadores oficiales encuentra su origen en la Ley 6 de 1945, hoy consagrada en el Artículo 432.1 CST. ${ }^{9}$ Además, el Artículo 467 CST instituye:

Convención colectiva de trabajo es la que se celebra entre uno o varios empleadores o asociaciones patronales, por una parte, y uno o varios sindicatos o federaciones sindicales de trabajadores, por la otra, para fijar las condiciones que regirán los contratos de trabajo durante su vigencia.

Respecto a la negociación colectiva de los empleados públicos, la situación es más compleja. En primer lugar, hay que precisar que el alcance del Artículo 55 CPC se extendió a la negociación colectiva de los empleados públicos ${ }^{10}$ y que el Convenio 151 de la OIT sobre las relaciones de trabajo en la Administración pública forma parte de la legislación interna,

9 Según el cual, "siempre que se presente un conflicto colectivo que pueda dar por resultado la suspensión del trabajo, o que deba ser solucionado mediante el arbitramento obligatorio, el respectivo sindicato o los trabajadores nombrarán una delegación de tres de entre ellos para que presente al (empleador), o a quien lo represente, el pliego de las peticiones que formulan". "De tres de entre ellos" fue declarado inexequible por la Sentencia C-797/00 (Corte Constitucional, 2000c, p. 13).

10 "Al analizar el artículo 55 de la Carta, la Sala encuentra que la norma constitucional garantiza el derecho de 'negociación colectiva' para regular las relaciones laborales, incluidas las organizaciones sindicales de los empleados públicos" (Corte Constitucional, 2005, p. 26). 
en virtud del Artículo 53 CPC. Sin embargo, el Artículo 416 CST prohíbe a los sindicatos de empleados públicos presentar pliegos de peticiones, es decir, iniciar una demanda de negociación y celebrar convenciones colectivas. Los sindicatos solo pueden presentar memoriales respetuosos o simples solicitudes (Villegas Arbeláez, 2014). Conviene precisar que el CST se elaboró en 1950 bajo los principios de la Constitución de 1886, que no incluía derechos sociales. Pues bien, la Corte Constitucional matizó esta disposición y, en una serie de pronunciamientos, declaró condicionalmente constitucional el Artículo 416 del CST (Corte Constitucional, 1998; 2000a). En consideración de su compatibilidad con los Convenios de la OIT, los jueces afirman que el Artículo 55 CPC contempla excepciones legales a la negociación colectiva y fundamenta al Artículo 416 del CST. Recalcan:

[...] debe tenerse en cuenta que si bien la negociación no es plena, porque se entiende que la decisión final le corresponde adoptarla a las autoridades señaladas por la Constitución, esto no implica que los sindicatos de estos servidores públicos no puedan desarrollar instancias legítimas para alcanzar una solución negociada y concertada en el caso de conflicto entre los empleados públicos y las autoridades (Corte Constitucional, 2005, p. 25). ${ }^{11}$

En la Sentencia C-201/02, se puede leer:

[...] la Corte debe advertir que, estando garantizado constitucionalmente el derecho de negociación colectiva para todas las relaciones laborales, incluidas las de los empleados públicos, y existiendo una amplia facultad de configuración normativa en esta materia por parte del legislador, este último podría en el futuro permitirlo a dichos empleados presentar pliegos de condiciones (sic) (Corte Constitucional, 2002, p. 33).

11 La constitucionalidad del dispositivo no implica "la prohibición del derecho de los sindicatos de empleados públicos de realizar negociaciones colectivas, en el sentido amplio del concepto. Por el contrario, estas organizaciones pueden presentar reclamos, peticiones, consultas, y deben ser atendidas. Los sindicatos de empleados públicos pueden acudir a todos los mecanismos encaminados a lograr la concertación sobre sus condiciones de trabajo y salarios". 
Por consiguiente, resulta llamativa la intervención del Poder Ejecutivo, que asumió la iniciativa en la materia a partir de 2009 mediante tres Decretos específicos expedidos en cinco años. Sin entrar en detalles, podemos considerar que el Decreto 535/2009 del 24 de febrero, del gobierno Uribe, carecía de objeto y constituyó una chapuza jurídica. Se trataba de un decreto "por el cual se reglamenta el artículo 416 del Código Sustantivo de Trabajo", Artículo que, como hemos visto, prohíbe la negociación colectiva de los empleados públicos (Villegas Arbeláez, 2014). Empujado por un acuerdo laboral tripartito del 26 de mayo de 2011, ${ }^{12}$ se aprobó el Decreto 1092/2012, del 24 de mayo que, sin referirse expresamente al Convenio OIT 151, representó "un avance, limitado, pero avance, en la perspectiva del Derecho de Negociación Colectiva, que ahora se denomina y reconoce asi" (Villegas Arbeláez, 2014, p. 238). De nuevo, tras la firma de otro acuerdo tripartito y bajo presión de la OIT, ${ }^{13}$ se promulgó el Decreto 160/2014 del 5 de febrero, sobre negociación colectiva en la Administración pública, ${ }_{14}^{14}$ que centrará el propósito de este trabajo. Sin duda, el uso de la vía reglamentaria plantea problemas, ya que, como hemos visto la regulación del derecho a la negociación colectiva constituye una materia en la cual existe una reserva legal.

\section{Los actores de la negociación y la eficacia del producto negociado}

\subsection{Los elementos de convergencia: la unidad del pliego de petición}

Sin importar si se trata de la negociación de los empleados públicos o del sector privado, un momento clave del proceso de negociación radica

12 Artículo 5.4 relativo a la negociación en el sector público: "Concertar con las centrales obreras y expedir un Decreto que reforme el Decreto 535 de 2009".

13 En el año 2007, el Comité de Libertad Sindical de la OIT había pedido, como hizo años anteriores, que se modificara el Artículo 416 del Código Sustantivo del Trabajo, para que se respetara el derecho a la negociación colectiva de los funcionarios públicos (véase $346^{\circ}$ informe del Comité, párrafos 396 a 424).

14 Dicho Decreto se promulgó tras nueve meses de negociación, que desembocaron en la firma del Acuerdo colectivo nacional para los empleados públicos de Colombia, en el marco del Decreto 1092 de 2012. 
en la determinación de los actores que van a negociar, es decir, en la conformación de la mesa de negociación.

El Derecho español puede constituir un marco de reflexión pertinente, ya que distingue con claridad dos cuestiones: por una parte, la capacidad de negociación, que se puede definir como la "aptitud general y abstracta" para formar parte de la negociación de un convenio en un ámbito dado y, por otra, la legitimación de negociación, que "supone un grado suplementario de concreción" (Agut, 1997, p. 378) y permite determinar concretamente los actores que participan en ella. Puede distinguirse la capacidad convencional como "aptitud genérica" para iniciar un proceso de negociación y la legitimación como aptitud para participar en una negociación concreta (Valdés Dal-Ré, 1988). La cuestión de la capacidad convencional es un paso previo y necesario a la apreciación de la legitimación. ${ }^{15}$

En el Derecho colombiano, ambos dispositivos se ciñen a la primera cuestión y evocan la capacidad convencional. En el sector privado, el Artículo 467 CST se refiere a "uno o varios patronos o asociaciones patronales, por una parte, y uno o varios sindicatos o federaciones sindicales de trabajadores, por la otra". En la negociación de los empleados públicos, de manera general, las partes negociadoras son, independientemente del ámbito considerado, las mismas, o sea, representantes de la Administración y representantes sindicales de los empleados públicos. ${ }^{16}$ Así, podemos considerar que la parte a la negociación colectiva que representa a los trabajadores es, de manera constante, el sindicato. ${ }^{17}$

Ninguna exigencia suplementaria está contemplada. Esta situación resulta problemática, dado el reconocimiento del pluralismo sindical en Colombia. En efecto, en una empresa o en una Administración pública, pueden coexistir varios sindicatos cuya capacidad de representación puede variar. Para compensar la ausencia de exigencia suplementaria en cuanto a

15 La noción de legitimación en España se restringe a la cuestión de la negociación colectiva y permite contemplar dos elementos: la representatividad sindical y la exigencia mayoritaria.

16 “Partes en la negociación. Pueden ser partes en la negociación: 1. Una o varias entidades y autoridades públicas competentes, según la distribución constitucional y legal y, 2. Una o varias organizaciones sindicales de empleados públicos" (Presidencia de la República, 2014b, art. 6).

17 Ya abordaremos más adelante la cuestión de los pactos colectivos y de la intervención directa de los trabajadores. 
la selección de los firmantes de la convención, interviene la regla de unidad de pliego de petición.

En la negociación de los empleados públicos, la presentación de un solo pliego de petición y el modo de formación de la comisión de negociación del lado salarial hacen imprescindibles la coordinación y articulación de actividades previas entre sindicatos, como lo subraya el Artículo 8 del Decreto 160/2014. En efecto, ningún sindicato puede estar excluido de la presentación de un solo pliego de petición; todos participan. Se prevé que "el número de integrantes de la comisión negociadora sindical debe ser razonablemente proporcional al ámbito de la negociación" (Presidencia de la República, 2014b, art. 9). El dispositivo del Decreto remite, por lo tanto, a la autonomía sindical la facultad de constituir la comisión sindical del bando salarial y opta por la constitución de una sola mesa de negociación integrada por los representantes de todos los sindicatos que presentaron el pliego. ${ }^{18}$

En el sector privado, de acuerdo con el Artículo 467 CST, pueden negociar convenciones colectivas un sindicato o varios y las federaciones sindicales, de un lado y, de otro, un empleador, varios o una asociación patronal. La coexistencia de varios sindicatos en una empresa ha planteado dificultades que conviene ahora detallar y resolver.

Antes del Decreto 89/2014, tras admitir que podían coexistir varios sindicatos de la misma clase o actividad en una misma empresa (Corte Constitucional, 2000b), se permitía a todos ellos presentar su pliego de petición y, por lo tanto, negociar y firmar una convención (Corte Constitucional, 2008a); en consecuencia, podía existir en una empresa una multiplicidad de convenciones (Corte Suprema de Justicia, 2008; Corte Constitucional, 2008a; 2000c; 2000b). Solo en el caso de que un sindicato contara con más de dos tercios de los trabajadores como afiliados se posibilitaba un solo proceso de negociación conducido por este sindicato mayoritario.

Esta situación planteaba varias dificultades. En primer lugar, si se considera que un trabajador podía estar afiliado a varios sindicatos ${ }^{19} \mathrm{con}$

18 En caso de imposibilidad de acuerdo entre los sindicatos, se establece, de forma subsidiaria, que debe aplicarse una regla de distribución "objetiva y proporcional al número de afiliados con derecho y pago de su cuota sindical depositada en banco conforme a los artículos 393 y 396 del código sustantivo de trabajo y según certificación del tesorero y secretario" (Presidencia de la República, 2014b, art. 9).

19 La Sentencia C-797 de 2000 declaró inconstitucional el Artículo 360 CST, según el cual 
capacidad de negociar su propia convención, de forma aislada, quedaba por determinar el estatuto convencional del trabajador. ${ }^{20}$ En segundo lugar, la variedad de procesos de negociación provocaba la atomización del movimiento sindical y, por lo tanto, su debilitamiento. En tercer lugar, es indubitable que la diversidad de convenciones colectivas en una empresa constituía un elemento nefasto y perjudicial para el empleador en cuanto a la gestión del personal y a la buena marcha de la empresa, lo que representaba un obstáculo a la productividad y a la eficacia económica.

En este contexto se promulgó el Decreto 89/2014 del 20 de enero de 2014, por el cual se reglamentan los numerales 2 y 3 del Artículo 374 del Código Sustantivo del Trabajo. Este Decreto establece el principio de unidad de negociación ${ }^{21} \mathrm{y}$, del mismo modo que en materia de negociación de los empleados públicos, prevé:

[...] si no hubiere acuerdo, la comisión negociadora sindical se entenderá integrada en forma objetivamente proporcional al número de sus afiliados y los diversos pliegos se negociarán en una sola mesa de negociación para la solución del conflicto, estando todos los sindicatos representados en el procedimiento de negociación y en la suscripción de la convención colectiva. Los sindicatos con menor grado de representatividad proporcional al número de sus afiliados, tendrán representación y formarán parte de la comisión negociadora.

Sin entrar en más valoraciones, consideramos que representa un avance positivo, ya que evita la atomización sindical, permite la uniformización

\footnotetext{
"se prohíbe ser miembro a la vez de varios sindicatos de la misma clase o actividad" (Corte Constitucional, 2000c).

20 La Corte Suprema de Justicia aportó respuesta y consideró que "aun cuando es viable jurídicamente que un trabajador pueda ser parte de varios sindicatos, en caso de que existan diversas convenciones colectivas suscritas por las organizaciones que integra, y de las cuales un mismo trabajador sea beneficiario de todas ellas, ello no significa que pueda aprovecharse simultáneamente de cada una, pues la libertad sindical debe entenderse para tales efectos, como que el asalariado debe escoger entre los distintos convenios aquel que mejor le convenga a sus intereses económicos, ello con el fin de evitar que el trabajador reciba duplicidad o más beneficios convencionales" (Corte Suprema de Justicia, 2009, p. 35).

21 El Decreto dispone que, en adelante, "Cuando en una misma empresa existan varios sindicatos, estos, en ejercicio del principio de la autonomía sindical, podrán decidir, comparecer a la negociación colectiva con un solo pliego de peticiones, e integrar conjuntamente la comisión negociadora sindical" (Presidencia de la República, 2014a, art. 1).
} 
de las condiciones de trabajo en la empresa a todos los trabajadores sindicalizados y racionaliza el proceso de negociación, por lo que aumenta la productividad en la empresa.

A modo de conclusión, ambos dispositivos asumen al sindicato como interlocutor de la parte salarial en los procesos de negociación colectiva sin exigencia a priori, relativa a su capacidad de representación. Todos los sindicatos pueden participar y firmar un acuerdo. En lo que se refiere a la composición de la comisión de negociación, recurren al principio de autocomposición de las partes negociadoras y señalan, en caso de desacuerdo, la aplicación del principio de proporcionalidad en función del número de afiliados.

\subsection{Los elementos de divergencias: un producto negociado de eficacia variable}

La eficacia del producto negociado permite contemplar su valor jurídico (eficacia jurídica) y sus destinatarios (eficacia personal), es decir, cómo y a quién se aplica.

En cuanto a la eficacia jurídica, cabe recordar que el surgimiento de la figura convencional -y más de la dimensión colectiva del Derecho del trabajo- se origina y fundamenta en la necesidad de llevar al ámbito colectivo la negociación de las condiciones de trabajo, para compensar el desequilibro consubstancial de la relaciones individuales y así garantizar la mejor protección a los trabajadores (Supiot, 1996a). Las relaciones entre el contrato de trabajo y el instrumento colectivo han centrado la atención de la doctrina e implican tratar la eficacia jurídica de la convención colectiva, o sea, cómo se aplica el producto de la negociación colectiva a las relaciones individuales de trabajo incluidas en su ámbito de aplicación. Existen dos alternativas: la eficacia normativa o real y la eficacia contractual.

En virtud de la eficacia normativa o real, el contenido del convenio se aplica automáticamente a las relaciones individuales de trabajo, sin necesidad de pactos entre las partes afectadas (empresario-trabajador). Asimismo, el convenio se impone sobre el contrato individual y las cláusulas contractuales que establecen condiciones peores para el trabajador son nulas. Por lo tanto, el efecto imperativo expresa la superioridad jerárquica de la convención colectiva de trabajo respecto a los contratos de trabajo 
(Morin, 1993; Gernigon, Odero y Guido, 2000). En caso de incumplimiento, conviene buscar la responsabilidad del sujeto incumplidor (empresario o trabajador) ante el orden social de la jurisdicción.

Sobre la eficacia contractual, el convenio crea obligaciones para los firmantes y su aplicación a terceros precisa un acuerdo explícito entre ellos; por eso, cabe pactar condiciones peyorativas en el contrato individual. En caso de incumplimiento, solo son responsables los sujetos firmantes.

En referencia a la eficacia personal del convenio, si este afecta a todos los sujetos de un determinado ámbito territorial y funcional (o profesional), tiene eficacia general o erga omnes. Si atañe en exclusiva a los sujetos firmantes o a los vinculados a estos, tiene eficacia limitada. Se trata, pues, de determinar cuáles son las relaciones individuales de trabajo incluidas en el ámbito de aplicación del producto de la negociación colectiva.

En todo caso, es oportuno dejar claro que eficacia jurídica y eficacia personal son dos nociones distintas y autónomas (Rojas Miño, 1998).

En este marco, el análisis de los dispositivos establecidos en el sector público y en el sector privado permite subrayar una importante diferencia que obliga a abordar cada uno de ellos.

\subsubsection{La eficacia normativa limitada de la convención colectiva en el sector privado}

Según el Artículo 16 CST, "las normas sobre trabajo, por ser de orden público, producen efecto general inmediato, por lo cual se aplican también a los contratos de trabajo que estén vigentes o en curso en el momento en que dichas normas empiecen a regir". ${ }^{22}$ De acuerdo con el Artículo 467 del CST, la convención colectiva tiene como objeto "fijar las condiciones que regirán los contratos de trabajo". Tras la lectura de estos dos Artículos, podemos afirmar que la convención colectiva de trabajo despliega una eficacia normativa, pues rige de forma automática e imperativa a los contratos de trabajo incluidos en su ámbito de aplicación. La convención se impone a los contratos de trabajo (Corte Constitucional, 1994). Por una parte, el 
contrato de trabajo no puede modificar in peius una cláusula convencional $y$, por otra, los derechos reconocidos en la convención resultan indisponibles. En lo que se refiere al efecto automático, implica que las disposiciones convencionales se sustituyen a las cláusulas contractuales contrarias. ${ }^{23}$ En todo caso, la aplicación automática e imperativa de la convención colectiva de trabajo, que traduce su eficacia normativa, permite rechazar la teoría de la incorporación del contenido convencional al contrato individual de trabajo, ya que la convención se aplica a partir del momento en que el trabajador se incluye en su ámbito de aplicación, sin que se precise alguna manifestación de voluntad. La convención es exterior al contrato, que permanece autónomo.

La cuestión relativa a la eficacia personal del convenio colectivo goza de un mayor tratamiento legal. Se han de contemplar varias posibilidades:

1) Si el número de trabajadores afiliados al sindicato es inferior a la tercera parte del total de trabajadores de la empresa, la convención se aplica a los trabajadores afiliados al sindicato que la haya celebrado o a los trabajadores que luego se adhieran al sindicato (art. 470 CST). También es posible la adhesión expresa individual y la práctica según la cual el empleador opta por aplicar a todos los trabajadores una convención firmada con sindicatos minoritarios. ${ }^{24}$

2) Cuando en la convención colectiva sea parte un sindicato cuyos afiliados excedan de la tercera parte del total de los trabajadores de la empresa, las normas de la convención se extienden a todos los trabajadores de la misma, sean o no sindicalizados.

2. Lo dispuesto en este artículo se aplica también cuando el número de afiliados al sindicato llegare a exceder del límite indicado, con posterioridad a la firma de la convención (art. 471 CST). Los trabajadores

23 El futuro de las cláusulas contractuales puede variar. En España, pueden ser declaradas nulas (art. 3.1 c y 9.1 del Estatuto de los Trabajadores) y en Francia, resultan inaplicables de forma provisional, mientras se aplica la convención colectiva (Corte de casación, Sala de lo Social, 17 de julio de 2001).

24 "[...] los preceptos legales sobre extensión de la convención a terceros constituyen un mínimo de derechos que puede ser mejorado por la obligación que contrae el empleador de manera libérrima [...] no sobra agregar que con arreglo al art. 68 de la Ley 50 de 1990, en los casos en que un trabajador no sindicalizado se beneficie de la normatividad colectiva, deberá pagar al sindicato respectivo durante su vigencia la cuota sindical ordinaria correspondiente" (Corte Suprema de Justicia, 1994). 
no sindicalizados pueden renunciar expresamente a los beneficios del acuerdo (Corte Suprema de Justicia, 2004). Si pierde su carácter mayoritario, la convención pasará a aplicarse según las reglas del Artículo 470 CST.

3) Extensión por acto gubernamental cuando se trata de una convención por rama (art. 472 CST). ${ }^{25}$

En definitiva, puede admitirse que el principio general es la eficacia limitada de la convención colectiva de trabajo. Cuando existe un sindicato "mayoritario", la convención va a desplegar una eficacia general. Sin embargo, si los trabajadores no sindicalizados pueden renunciar a la aplicación de la convención mediante una manifestación expresa en tal sentido, el dispositivo legal opta por dejar siempre la facultad al trabajador de someterse a la convención considerada, lo que revela un recelo sintomático hacia la elevación colectiva de la determinación de las condiciones de trabajo. Podemos traer a colación una sentencia de la Corte Constitucional, referente al principio de la eficacia limitada de la convención, según la cual, "si la mayoría de trabajadores de una empresa ha decidido no sindicalizarse, ese derecho debe respetársele. Una manifestación de esa protección, consiste, precisamente, en que el acuerdo suscrito entre el patrono y el sindicato no se les aplique" (Corte Constitucional, 1996b, p. 48). Es lamentable que los jueces confundan afiliación sindical y cobertura convencional y que no hayan tomado en cuenta el carácter más favorable o no de la convención. En tanto la convención otorga más beneficios o ventajas a los trabajadores, cualquiera tendría que poder beneficiarse de ella, con independencia de su vínculo sindical. El deseable aumento de la tasa de cobertura convencional no ha de pasar necesariamente por un aumento de la tasa de afiliación sindical, como parecen entender los jueces constitucionales. El ejemplo francés, que abordaremos más adelante, ilustra esta posición.

25 "1. Cuando hayan convenciones colectivas que comprendan más de las dos terceras partes de los trabajadores de una rama industrial en una determinada región económica, el Gobierno puede hacerlas extensivas, en todo o en parte, a las demás empresas de la misma industria de esa región, que sean de igual o semejante capacidad técnica y económica, pero siempre que en dichas empresas no existan convenciones que consagren mejores condiciones para los trabajadores [...]" (art. 472, CST). 


\subsubsection{La norma negociada para los empleados públicos}

El acuerdo firmado entre los sindicatos y los órganos de la Administración correspondientes debe ser depositado en el Ministerio del Trabajo, dentro de los diez días siguientes a su celebración, para efectos de registro administrativo y de prueba (Presidencia de la República, 2014b, art. 13). Incumbe a la entidad pública considerada expedir el acto administrativo para el cumplimiento del acuerdo en los veinte días hábiles siguientes a la suscripción (Presidencia de la República, 2014b, art. 14).

Se distinguen dos etapas. En primer lugar, una vez firmado y mientras no se expida el acto administrativo o la ley para su cumplimiento, el acuerdo despliega una eficacia meramente obligacional, es decir, obliga a sus firmantes. La postura según la cual una entidad no expide el acto o no puede aprobar la ley correspondiente permite dar cuenta de ello. Sin bien el Decreto no le ha prestado atención a esta cuestión, podemos pensar que no queda otra respuesta que admitir que el sindicato o los sindicatos firmantes podrían desplazar el conflicto en el ámbito político y recurrir al juez para "esperar" una sentencia favorable que obligue a la Administración a cumplir con lo estipulado en el acuerdo, desde una responsabilidad meramente contractual.

En segundo lugar, ya transcrito a un acto administrativo o una ley, el acuerdo tendrá eficacia normativa y general, pues se convierte en norma jurídica y en derecho objetivo, aplicable a todos los funcionarios y empleados de vínculo legal y reglamentario, sin excepción o distinción alguna. La existencia o no de un vínculo sindical es, por lo tanto, irrelevante. El acto de transcripción es inexcusable para que el acuerdo despliegue una eficacia normativa y general que supere su dimensión contractual u obligacional. Su aplicación se produce por instrumentalización: su transformación en ley o acto administrativo, según el ente administrativo del que se trate. ${ }^{26}$ Conviene tener presente la distinción entre contenido normativo y obligacional del acuerdo. Solo el contenido normativo gozará de la eficacia general y será objeto de la transcripción o aprobación legal o reglamentaria.

La eficacia general constituye una exigencia conforme a la necesaria homogeneidad de las condiciones de trabajo de los empleados públicos

26 Pueden ser actos administrativos o presentación de proyectos de ley, ordenanza o acuerdo municipal (Presidencia de la República, 2014b, art. 14). 
y garante del respeto a los principios de igualdad, no discriminación e imparcialidad que han de guiar la Administración pública (Roqueta, 2007). En todo caso, si asumimos que la ley o el acto reglamentario se limita a transponer el contenido del acuerdo, podemos hablar de:

[...] un tipo de "norma negociada" que, como es lógico, debe tener el rango jerárquico correspondiente al órgano que lo ratifica, insertándose con dicho rango en el ordenamiento jurídico, y que puede derogar, modificar o sustituir las normas reglamentarias, que hasta su celebración hayan venido regulando las mismas materias (Roqueta, 2007, p. 475). ${ }^{27}$

Admitida la aplicación del acuerdo con eficacia normativa y general, aunque mediante la ineludible transposición legal o reglamentaria, es preciso formular una observación sobre los firmantes por parte de la representación de los empleados públicos. Se establece la unidad de negociación mediante la presentación de un solo pliego de petición. Sin embargo, no se indica exigencia alguna de legitimación. Por lo tanto, un solo sindicato minoritario, con una tasa de afiliación muy baja, en una Administración pública considerada podría negociar un acuerdo que cobijara a todos los empleados públicos incluidos en su ámbito de aplicación.

En el sector privado, las reglas relativas a los firmantes del acuerdo son similares. No obstante, la aplicación con eficacia general de la convención no está garantizada y existe, por lo tanto, una especie de doble rasero. Si los firmantes son los mismos y cumplen las mismas exigencias, ¿por qué la eficacia del acuerdo alcanzado no es la misma? De estas problemáticas vamos a tratar a continuación.

27 El hecho de hablar de "norma negociada" no ha de confundirse con otro proceso denominado "legislación negociada". Esta modalidad de ley específica se caracteriza por la incorporación del contenido de un acuerdo previo, firmado entre interlocutores sociales e implica, por lo tanto, una negociación anterior a la promulgación de la ley y sobre su contenido. La intervención de los interlocutores sociales prepara o acompaña las reformas legislativas y están asociados con el proceso de elaboración de la ley. La ley da un paso atrás, para otorgar más autonomía a los interlocutores sociales, que no dejan de ser los más competentes para legislar en materia de relaciones laborales (Valdés Dal-Ré, 1997; Supiot, 1996b). Sin lugar a dudas, este fenómeno reviste una dimensión política y sociológica y remite al proceso de concertación o de diálogo social. El proceso de negociación de las condiciones de trabajo se distingue de la legislación negociada por dos aspectos fundamentales. Por una parte, no negocian los interlocutores sociales, sino los sindicatos frente a la Administración, como empleadora. Por otra parte, el producto de la negociación no corresponde, en sentido estricto, a una ley que organiza las relaciones de trabajo, sino, más bien, a una ley o un reglamento regulador de las condiciones de trabajo en un ámbito específico y no general e impersonal. 


\section{Hacia la coherencia entre actores de la negociación y eficacia del producto negociado}

\subsection{La exigencia de representatividad de los negociadores}

La eficacia normativa y general desplegada por un acuerdo colectivo se relaciona con la noción de legitimación, cuyo primer escalafón es el concepto de representatividad sindical. Resulta muy llamativo que el CST no haga mención a esta última. No obstante, el modelo constitucional colombiano, así como el desarrollo legal o reglamentario, ofrece un marco en el cual esta noción sería útil y eficiente. La CPC consagra el principio de libertad sindical y desarrolla un modelo sindical pluralista que implica la necesaria elección de organizaciones capaces de representar a los trabajadores en las mejores condiciones. Jurídicamente, este proceso utiliza el concepto de representatividad sindical.

Surgió por primera vez en 1919, en el Artículo 389 del Tratado de Versalles, constitutivo de la OIT. No se estableció definición, lo que permitió a cada país determinar los criterios nacionales para designar a sus delegados en la OIT, siempre y cuando se tratara de criterios objetivos, preestablecidos y precisos que no pudieran tener como efecto prohibir la existencia de otros sindicatos, influir en la elección por los trabajadores de una organización sindical o privar a los sindicatos que no hubieran sido reconocidos como representativos de los medios esenciales para defender los intereses profesionales de sus miembros (OIT, 1994, p. 46).

La noción de representatividad es heterogénea y moldeable. Al hilo de las palabras del profesor Valdés Dal-Ré (1993):

[...] la representatividad es una noción polisémica, susceptible de apropiarse diversos sentidos; al menos, de los dos siguientes. La representatividad puede ser entendida, primeramente, como un medio para acreditar capacidad de representación de los intereses de un grupo de trabajadores, de modo que sindicato representativo vale tanto como sindicato dotado de capacidad para ejercer acción sindical. Pero la representatividad puede ser empleada, en segundo lugar, como instrumento de selección de organizaciones sindicales, de valoración comparativa entre ellas, de modo que sindicato representativo ya no alude a la capacidad de ejercicio de 
acción sindical, sino a una mejor o más eficaz capacidad respecto de los restantes sindicatos (p. 92).

Al tomar como referencia el segundo sentido, se procede a una organización del sistema de relaciones colectivas de trabajo con el objetivo de racionalizar, canalizar e institucionalizar un conflicto estructural y consubstancial entre trabajadores y empleadores. El reconocimiento del carácter representativo de un sindicato se ha de acompañar de la atribución de prerrogativas especiales que el Estado le otorga respecto a los otros sindicatos. Así, la representatividad constituye "un título de relevancia del orden profesional para el orden estatal" (Yannakourou, 1995, p. 100), es externa a la autonomía colectiva y representa un "título de legitimidad" atribuido por el Estado (Verdier, 1991, p. 7), una herramienta jurídica a su disposición (García Murcia, 1987). En todo caso, los sindicatos no representativos tienen reconocido el derecho a la negociación colectiva y el derecho de huelga. No hay dudas en cuanto a la conformidad de la representatividad sindical con los principios fundamentales del derecho sindical, es decir, a los principios de igualdad entre sindicatos y de pluralismo sindical. ${ }^{28} \mathrm{La}$ existencia y la utilidad del concepto de representatividad no se prestan a discusión y se revelan como "una noción indispensable a una sana práctica del pluralismo sindical" (Verdier, 1987, p. 486) que responde a exigencias sociales, económicas y jurídicas (Casas Baamonde, 1988).

La diferencia entre sindicatos representativos y no representativos reside en el alcance, la intensidad y la configuración de estos derechos y prerrogativas. En materia de negociación colectiva, la distinción entre ellos podría radicar en la eficacia personal del producto negociado.

A continuación, es oportuno mencionar la noción de interés colectivo, que otorga al carácter representativo del sindicato una dimensión suplemen-

28 En España, el Tribunal constitucional ha reconocido la compatibilidad de estas disposiciones con los otros derechos constitucionales y su conformidad con las normas internacionales (STC 73/1984 de 27 de junio y, en especial, STC 98/1985 de 29 de julio). Para profundizar, puede verse Navarro Nieto (1993). El principal riesgo al cual se enfrenta la utilización de la noción de representatividad es la desconexión y la distensión con la noción de representación. Además, la doctrina subraya que esta relación entre Estado y sindicato, con el fin de permitir la "gobernabilidad del sistema político", tiene el riesgo de fomentar el neocorporativismo mediante un doble intercambio: reconocimiento como interlocutores privilegiados por parte del Estado a determinados sindicatos contra el compromiso de aquellos sindicatos de neutralizar y controlar los conflictos sociales y respetar lo pactado (Valdés Dal-Ré, 1988). 
taria y se distingue de la suma de los intereses de los miembros de un sindicato y del interés general. El sindicato defiende un interés propio: el interés colectivo de la profesión. Su defensa constituye la base de la acción sindical, su razón de ser. Así, el reconocimiento del interés colectivo se acompañó con un poder atribuido a los sindicatos para representar a los trabajadores mediante prerrogativas legalmente previstas (Navarro Nieto, 1993), que se refieren a dos aspectos: a la representación orgánica o institucional frente al Estado y al empresario y a la representación convencional mediante la negociación y firma de convención colectiva de trabajo (Verdier, 1991).

El carácter representativo implica algo más: la capacidad, en casos determinados legalmente, de asumir la representación del interés colectivo de los trabajadores en su conjunto, o sea, sin tener en cuenta la existencia de un vínculo de afiliación entre el sindicato y los trabajadores (Navarro Nieto, 1993). De este modo, podrían superarse las limitaciones de la representación sindical enfocada hacia el vínculo de afiliación y atribuir a los sindicatos representativos la representación de todos los trabajadores y no solo de sus afiliados. La representación del interés colectivo se acerca, entonces, a la noción de representación del Derecho público y toma un significado más político (Morin, 1988), que remite a la concepción "esencialista" del sindicato (Rosanvallon, 1988). Cada sindicato representativo tiene calidad para expresarse en nombre del interés colectivo de la profesión y puede, por lo tanto, firmar una convención aplicable al conjunto de los trabajadores.

La Corte Constitucional colombiana no parece dirigirse hacia una concepción extensiva del papel del sindicato en la cual pueda representar al conjunto de los trabajadores, ya que considera que los sindicatos tienen como "misión propia [...] "representar y defender los intereses económicos comunes de sus afiliados" (Corte Constitucional, 1994). ${ }^{29}$ Se inclina hacia la regulación de la acción sindical mediante el derecho común de la representación. Sin embargo, el Artículo 10 del Convenio 87 de la OIT enuncia que "en el presente Convenio, el término organización significa toda organización de trabajadores o de empleadores que tenga por objeto fomentar y defender los intereses de los trabajadores o de los empleadores" (OIT, 1948).

29 Asimismo, puede verse Corte Constitucional (2008a; 2008c) 
El dispositivo colombiano menciona el término de representatividad de forma puntual y sin definirlo. La Ley 278 de 1996, relativa a la Comisión permanente de concertación de políticas salariales y laborales señala, en su Artículo 5, literal c, modificado por el Artículo 1 de la Ley 990 de 2005, que en representación de los trabajadores formarán parte de la comisión:

Tres (3) representantes, con sus respectivos suplentes personales, designados o removidos por las Confederaciones Sindicales más representativas del País, determinadas con base en el número de afiliados que cada una de estas posea al momento de la elección, según el censo que en tal sentido elabore el Ministerio de la Protección Social. ${ }^{30}$

Por lo tanto, el proceso de selección entre sindicatos se realiza en vista de las relaciones con el Estado en la modalidad de representación institucional. Asimismo, el Artículo 9 del Decreto 160/2014 habla de "grado de representatividad sindical y conformación de la comisión negociadora", pero se limita a remitir a la autonomía sindical la formación de la comisión y, en caso de desacuerdo, indica el principio de proporcionalidad en función del número de afiliados. No prevé algún umbral que permita conocer la representatividad de cada sindicato. Por último, el Decreto 89/2014, en su Artículo 1 in fine dispone que "los sindicatos con menor grado de representatividad proporcional al número de sus afiliados, tendrán representación y formarán parte de la comisión negociadora", sin aportar elementos para definir la representatividad. En todo caso, llama la atención que el CST no mencione la noción de representatividad o el término "representativo". Es cierto que establece una diferencia entre sindicatos con base en el número de afiliados respecto al personal de la empresa y que condiciona la aplicación general de la convención colectiva (CST, arts. 470-471). ¿Por qué no se hace la misma exigencia cuando se trata de negociación en el sector público, ya que el producto negociado se va a aplicar a todos los funcionarios?

Cabe subrayar que la ausencia de criterios de medición de la capacidad de representación de un sindicato en una empresa no es total. La regulación relativa a la creación de sindicatos en una empresa o en una Administra-

30 Mediante la Ley 1444 de 2011, el Ministerio de la Protección Social fue escindido en dos: el Ministerio de Trabajo y el Ministerio de Salud y de Protección Social. 
ción pública conlleva una presencia sindical, pues implica la presencia de al menos veinticinco trabajadores afiliados. ${ }^{31}$ Sin entrar en detalles, pues nos extenderíamos más allá del objetivo de este trabajo, consideramos que es difícil justificar el establecimiento del mismo número de afiliados para un sindicato de industria y para un sindicato de empresa. Además, en las pequeñas y medianas empresas, este número torna imposible la presencia sindical, bien porque no cuenta con veinticinco trabajadores o porque implica una altísima cantidad de trabajadores afiliados. En realidad, parecen confundirse dos cuestiones distintas. Por un lado, se trata de la creación de un sindicato por el cual la fijación de un número único de veinticinco trabajadores se ve arbitrario y excesivo y, por otro, se trata de medir la capacidad de representación de un sindicato, es decir, su representatividad. En definitiva, a pesar de los argumentos - poco convincentes, a nuestro parecerde la Corte Constitucional, ${ }^{32}$ estimamos que si el legislador colombiano hubiera querido obstaculizar la presencia y el fomento sindical, no hubiera podido hacerlo de mejor forma. Al contrario, se podría fijar un número de afiliados más reducido en el momento de la creación del sindicato, lo que facilitaría su institución en las empresas y fijar un número de afiliados en un porcentaje del total de trabajadores, para medir su representatividad.

Surge otra dificultad, nos referimos al criterio que permite detectar la representatividad sindical. Dos vías permiten reconocer a un sindicato como representativo: la verificación de criterios legalmente definidos en lo que se denomina representatividad probada, efectiva o demostrada y la irradiación por afiliación a una organización sindical con mayor representatividad, lo que se denomina representatividad presumida (Cialti, 2013).

En Colombia, la representatividad presumida no se contempla, ya que el carácter de representativo no conlleva la atribución de prerrogativas

31 "Todo sindicato de trabajadores necesita para constituirse o subsistir un número no inferior a veinticinco (25) afiliados" (art. 359, CST), declarado exequible por la Sentencia C-201 de 2002 (Corte Constitucional, 2002).

32 La Corte basa su posición sobre el carácter razonable del requisito y lo considera necesario y proporcionado a la finalidad que persigue: garantizar una estructura y una organización mínimas y de carácter democrático, que permita al sindicato cumplir sus objetivos, hacer efectivo su normal funcionamiento, asignar a los miembros diversas funciones y garantizar la participación de todos los afiliados. Sin embargo, ¿cómo explicar que el sindicato no sea sometido a las mismas exigencias que las previstas para la creación de una asociación, fundación o sociedad civil sin motivos sindicales? Otra vez, no queda más remedio que evidenciar el recelo del legislador hacia la figura sindical (Corte Constitucional, 2002). 
especiales a las confederaciones sindicales, excepto su presencia en la Comisión permanente de concertación de políticas salariales y laborales. En lo referente a la representatividad probada, se aprecia conforme al principio de concordancia o correspondencia y los criterios han de ser guiados por las normas de la $\mathrm{OIT},{ }^{33}$ debido a una exigencia de objetividad. Aunque en Derecho positivo no se puede hablar explícitamente de representatividad, el criterio que pone en marcha el mecanismo de selección de sindicatos es el número de afiliados.

Si bien es cierto que el argumento de los afiliados tiene el visto bueno de la OIT (1978), hay que admitir que, de nuevo, el legislador colombiano no ha elegido el más propicio al fomento sindical. En efecto, en un clima de violencia y persecución del movimiento sindical (Correa Montoya, 2009; Zúñiga Romero, 2012), la postura acerca de la afiliación no deja de ser la menos apropiada para promover y reforzar el movimiento sindical. Si el propósito de la ley es neutralizar el desarrollo del sindicalismo, ha elegido con acierto. Además, aparte de este contexto propio de Colombia, el criterio de la afiliación plantea muchas dificultades. ${ }^{34}$ Dos aspectos merecen una particular atención. En primer lugar, es difícil compaginar y encontrar un punto de equilibrio entre el respeto a la libertad sindical y la necesaria verificación de la realidad de las cifras proporcionadas por un sindicato. Nos encontramos frente al sempiterno problema de la veracidad del número de afiliados presentado por un sindicato, ya que no se puede negar que la práctica sindical se muestra reacia a desvelar algunas informaciones, en especial los datos de afiliación. En segundo lugar, el punto nuclear de la cuestión reside en saber a quién se debe entregar la información pertinente: ¿a la autoridad administrativa o al juez? (Álvarez Cuesta, 2006). En el contexto colombiano, facilitar este tipo de datos a la Administración no es una opción adecuada. Se podría admitir que el sindicato deba presentar al juez el número de afiliados, así como los datos para su comprobación, en caso de litigio. Parece conveniente que el juez esté encargado de recibir los

33 Según el Comité de Libertad Sindical de la OIT, "los criterios en que se inspire la distinción entre organizaciones más o menos representativas tienen que ser de carácter objetivo y fundarse en elementos que no ofrezcan posibilidad de parcialidad o abuso" (OIT, 2006, párr. 347).

34 Los jueces franceses han afirmado que el argumento de los efectivos no puede considerarse como único criterio decisivo para reconocer o rechazar la representatividad de un sindicato (Corte de casación, Sala de lo Social, 4 de marzo de 1970). 
datos de afiliación del sindicato, pues el respeto del secreto de afiliación y la imposibilidad de identificar personalmente a los trabajadores sin su consentimiento han de guiar los dispositivos en los cuales el juez o un organismo tercero independiente tienen un papel central. Colombia adoptó la posición opuesta. El Artículo 365, literal f, CST, relativo al registro sindical obliga al sindicato a presentar la "nómina completa del personal de afiliados con su correspondiente documento de identidad" ante el Ministerio de Trabajo. ${ }^{35}$ Esta información transmitida en el momento de constitución del sindicato no tiene por qué ser actualizada. El Artículo 400 CST prevé que "los empleadores respectivos deduzcan de los salarios de los trabajadores afiliados y pongan a la disposición del sindicato, el valor de las cuotas ordinarias o extraordinarias con que aquellos deben contribuir", lo que facilita un control actualizado del número de afiliados por parte del empleador. Sin embargo, en caso de que el sindicato prefiera recaudar de forma autónoma o de que se trate de un sindicato de industria que supone la intervención de varios empleadores, la posibilidad de control del número actualizado de afiliados conlleva problemas.

Si se admite que el criterio de la afiliación sindical produce dificultades de orden práctico y también sociopolítico en el contexto colombiano, se podría adoptar otra postura. Sin que el paralelismo sea exacto, el ejemplo español al salir de la dictadura franquista es pertinente. Debido a un movimiento sindical en construcción, sin mucha implantación en las empresas como consecuencia de la represión franquista, con la finalidad de promover el sindicalismo en el nuevo marco democrático (Navarro Nieto, 1987), el legislador español optó por establecer el criterio de la audiencia electoral. Por otras razones, el movimiento sindical en Colombia enfrenta enormes tropiezos para estar presente en las empresas y para convertirse en un interlocutor fuerte ante el Estado. La adopción de la audiencia electoral para determinar los sindicatos con mayor representación podría ser una buena herramienta, pues permitiría superar los problemas inherentes al criterio de la afiliación y, sobre todo, garantizaría la legitimación de las actuaciones sindicales, en particular la firma de una convención que despliegue una eficacia normativa y general.

35 Modificado por el Artículo 4 de la Ley 584 de 2000. 
A continuación, abordaremos la oportunidad de la convención colectiva, en especial de empresa, de aplicarse a todos los trabajadores, sin contar con su afiliación sindical.

\subsection{La extensión de la eficacia del producto negociado en el ámbito privado}

La cultura sindical colombiana no ve con buenos ojos la aplicación general de una convención colectiva firmada por un sindicato minoritario para todo el personal de la empresa. Es cierto que dejar la facultad al empleador de decidir la ampliación de los avances conseguidos por un sindicato a todo el personal de la empresa no incentiva la afiliación e impide al sindicato recoger los frutos de su trabajo.

Según el Comité de Libertad Sindical de la OIT:

Cuando la extensión del convenio se aplica a los trabajadores no afiliados de las empresas cubiertas por la convención colectiva, dicha situación no plantea en principio problemas de contradicción con los principios de la libertad sindical, en la medida en que ha sido la organización más representativa la que ha negociado en nombre de la totalidad de los trabajadores y no se trata de empresas con una pluralidad de establecimientos (OIT, 2006, párr. 908).

A pesar de la falta de exigencia de representatividad en el caso colombiano, la Corte Suprema de Justicia ha admitido esta facultad del empleador (Corte Suprema de Justicia, 1994). Esta posición presenta aspectos positivos como el aumento de la tasa de cobertura convencional, que resulta imprescindible para asegurar una mejor protección de los trabajadores y fomentar la colectivización de las condiciones de trabajo, garante de un sistema de relaciones de trabajo justo y democrático. El punto de partida de esta reflexión consiste en contrarrestar la intervención unilateral del empleador e introducir el concepto de representatividad sindical, que atribuye a los sindicatos una capacidad de representación general de todos los trabajadores y no solo de sus afiliados.

En este marco, el dispositivo legal francés podría dar una pista interesante. En Francia, aunque el efecto relativo de los contratos se erija como 
principio, dos modalidades matizan su alcance y conducen a atribuir una eficacia personal general o erga omnes a la convención colectiva. Por una parte, existe el procedimiento administrativo de la extensión de la convención colectiva de industria, que otorga objetivamente una eficacia general o erga omnes a una convención de industria determinada que cumple ciertos requisitos (Cialti, 2013). Esta medida se enfoca en la actividad de la empresa y no en el empresario, al contrario de la segunda modalidad, que parece más pertinente para el caso colombiano, ya que se orienta al ámbito empresarial. Por otra parte, el Artículo L. 2254-1 CT asigna una eficacia general a una convención de empresa, centrada subjetivamente en la parte patronal. Este Artículo establece que "cuando el empleador está vinculado por las cláusulas de la convención colectiva de trabajo, estas cláusulas se aplican a los contratos de trabajo firmados con él". Además de dar fundamento a la eficacia normativa de la convención colectiva, este Artículo ofrece una excepción al principio del efecto relativo de los contratos, es decir, a la eficacia personal limitada de la convención colectiva y posibilita aplicar la convención "de pleno derecho a todos los trabajadores y sindicatos, sin distinción" (Corte de casación, 1991). La doctrina lo califica, por lo tanto, de "pequeño efecto general" (Pelissier, Lyon-Caen y Jeammaud, 2006, p. 750). Esta regla rige tanto si el empleador está vinculado a una convención de industria - por ser afiliado a la organización patronal firmante-36 como naturalmente a una convención de empresa, por ser firmante de ella. Así, la afiliación sindical del trabajador es indiferente y el empleador habrá de aplicar la convención a todo el personal de su empresa, lo que garantiza la unidad del estatuto colectivo.

La aplicación con eficacia general de la convención colectiva también ataja un problema endémico muy grave del Derecho colombiano: la existencia de los pactos colectivos regulados por el Artículo 481 CST. Aunque sea considerada por la jurisprudencia como una manifestación, no sin límites

36 Por consiguiente, un empleador que no es adherente o miembro de una asociación patronal firmante no ha de aplicar la convención; el principio de la eficacia relativa de los contratos sigue vigente y la convención despliega una eficacia personal limitada (Corte de casación, Asamblea Plenaria, 6 de abril de 1990). Al contrario, si es miembro de la asociación patronal firmante y la actividad de la empresa se encuentra en el ámbito de aplicación geográfico y funcional o profesional de la convención, estará vinculado a ella y habrá de emplearla en su empresa. Su eventual demisión posterior de la asociación no lo exonera de sus obligaciones y deberá seguir aplicando la convención (República francesa, 1956). 

como consecuencia de la doble perspectiva de la libertad sindical (Guerrero, 2011), ${ }^{37}$ la posibilidad ofrecida a trabajadores no sindicalizados de negociar y firmar contratos colectivos directamente con sus empleadores vulnera el derecho de libertad sindical y las normas internacionales de la OIT (Gernigon et al., 2000, p. 41). ${ }^{38}$ Las limitaciones previstas por el CST resultan, a toda luz, insuficientes, ${ }^{39}$ aunque la Corte Constitucional (1995) las haya avalado. ${ }^{40}$ Plantear la problemática hacia la posible consecuencia negativa en materia de afiliación sindical o hacia la situación de discriminación entre trabajadores es discutible, ya que es la libertad sindical, es decir, la capacidad de actuación de los sindicatos, la que se ve directamente afectada. ${ }^{41}$ Así, la única posibilidad por la cual podría admitirse la conclusión de tales pactos sería la ausencia de presencia sindical en la empresa. En cuanto es-

37 La vertiente negativa de la libertad sindical, es decir, el derecho de no afiliarse, no puede producir para los trabajadores no sindicalizados la privación del derecho a la negociación colectiva. No obstante, conviene apuntar que los trabajadores no sindicalizados pueden adherirse de forma individual a una convención colectiva.

38 El Comité de Libertad Sindical de la OIT reiteró varias veces su preocupación por un uso desviado de estos pactos y afirmó: "La recomendación sobre los contratos colectivos, 1951 (núm. 91), da preeminencia, en cuanto a una de las partes de la negociación colectiva, a las organizaciones de trabajadores, refiriéndose a los representantes de los trabajadores no organizados solamente en el caso de ausencia de tales organizaciones. En estas circunstancias, la negociación directa entre la empresa y sus trabajadores, por encima de las organizaciones representativas cuando las mismas existen, puede en ciertos casos ir en detrimento del principio por el cual se debe estimular y fomentar la negociación colectiva entre empleadores y organizaciones de trabajadores" (OIT, 2006, párr. 944). Para profundizar, puede verse Ostau de Lafont de León y Niño Chavarro (2012).

39 En primer lugar, se puede afirmar que la existencia de un sindicato de trabajadores que agrupe a más de la tercera parte de los trabajadores de la empresa no constituye un contrafuego suficiente. En segundo lugar, si dichos pactos pretenden desestimular la afiliación sindical, al atribuir a los beneficiarios no sindicalizados mejoras o beneficios no contemplados en una convención colectiva firmada en la misma empresa con sindicatos, el CST y el Código Penal prevén sanciones para el empresario (Artículo 354, literal a, CST, modificado por el Artículo 39 de la Ley 50 de 1990; en el ámbito penal, el Artículo 200 de la Ley 599 de 2000, modificado por el Artículo 5 Ley 1309 de 2009 y modificado por el Artículo 26 Ley 1453 de 2011).

40 " [...] lo que sí no le está permitido [al patrono] es utilizar estos mecanismos, para crear condiciones de trabajo para los trabajadores no sindicalizados diferentes a las previstas para los trabajadores sindicalizados, cuando las circunstancias fácticas no justifican desde el punto de vista de su diferencia, objetividad, racionalidad, razonabilidad y finalidad un tratamiento distinto, pues si lo hace lesiona los derechos a la igualdad, a la asociación sindical y a la negociación colectiva" (Corte Constitucional, 1996a, p. 12).

41 Resulta difícil hablar de negociación colectiva en caso de pactos colectivos, dado que la primera conlleva la idea de trabajadores como un solo grupo, que negocia mediante uno o varios representantes. 
té presente un sindicato, tendría que convertirse en el único interlocutor válido para el empresario.

La atribución a una convención colectiva firmada por un sindicato representativo, es decir, con capacidad de representación de todos los trabajadores y no solo de sus afiliados, conduciría a extender el beneficio de la convención a todo el personal de la empresa y a contrarrestar la oportunidad de trabajadores no sindicalizados para negociar otro tipo de acuerdos.

Han de formularse tres consideraciones. No se trata de abordar aquí estos aspectos que necesitarían un desarrollo propio y profundo; no obstante, es preciso mencionarlos para tener más elementos de comprensión y enmarcar la reflexión.

En primer lugar, para garantizar la capacidad de unión de los trabajadores de una empresa durante la negociación de una convención colectiva llevada a cabo por un sindicato representativo, es necesario superar la condición de afiliados o no al sindicato en cuestión. La unión de los trabajadores podría hacerse mediante el ejercicio del derecho de huelga (Ugarte, 2014); sin embargo, nos topamos con otra carencia preocupante del dispositivo legal colombiano, sin hablar del contexto sociopolítico, ya que las condiciones del ejercicio de huelga presentan limitaciones sustanciales que ponen en duda su realidad. De nuevo, el dispositivo legal, más que favorecer el desarrollo de un sistema de relaciones laborales democrático, conduce a su limitación.

En segundo lugar, es cierto que las ideas avanzadas en este texto no conducen a reforzar de manera directa la tasa de afiliación de los sindicatos, lo que conlleva a tomar en cuenta su financiación. En este punto, la mayoría de los sistemas de relaciones de trabajo de los países democráticos prevé una parte de financiación estatal y pública para garantizar la actuación de los sindicatos más importantes.

En tercer lugar, la noción de representatividad no implica una exigencia de mayoría, al contrario de la noción de legitimación. Ya sabemos que el Derecho colombiano se muestra muy exigente en la materia y establece una mayoría de dos tercios para que una convención colectiva firmada por un sindicato despliegue una eficacia general en la empresa. Dado el contexto del sistema laboral colombiano, la exigencia de mayoría no es imprescindible. En efecto, la firma de una convención colectiva de trabajo solo puede constituir una mejora de las condiciones de trabajo existentes que no exige 
necesariamente el respeto de una exigencia mayoritaria. La evolución del caso francés resulta muy ilustrativo en la materia (Cialti, 2013). En todo caso, podría imaginarse la posibilidad de recurrir a la figura del referendo, que permitiría al personal de la empresa aprobar una convención firmada por un sindicato representativo, pero no mayoritario.

\section{Conclusión}

En virtud del Artículo 55 CPC, mediante el legislador, el Estado ha de proporcionar un marco legal cuya finalidad es el fomento de la concertación, del diálogo y de la negociación colectiva como herramientas de resolución de conflictos. En este sentido, el legislador colombiano instituyó mecanismos de participación de los poderes públicos como en los casos del arbitramiento obligatorio para los servicios mínimos o de la intervención de los agentes del Ministerio de Trabajo en un conflicto colectivo. Esta visión paternalista debe ser superada, para dar paso a un marco legal que proporcione las herramientas jurídicas para que la autodeterminación de las partes se desarrolle de forma adecuada. Consideramos que el deber que incumbe al legislador solo está cumplido en parte, puesto que, como hemos intentando mostrar, el desarrollo de la negociación colectiva presenta muchas carencias en su desarrollo legal o reglamentario y varias incoherencias, cuando analizamos de forma paralela los regímenes jurídicos de la negociación colectiva de los empleados públicos y del sector privado.

Este trabajo no pretende aportar elementos definitivos de respuestas, sino dar pautas para un debate constructivo, consciente de que el aumento de la tasa de cobertura convencional es una exigencia ineludible para mejorar las condiciones de trabajo de millones de colombianos y colombianas.

En todo caso, los problemas del derecho a la negociación colectiva no pueden ser abordados de forma aislada. Los obstáculos legales a la creación de sindicatos, a la presencia sindical en las empresas, así como las restricciones difícilmente justificables al ejercicio del derecho de huelga son otros aspectos relevantes que obstaculizan el desarrollo de la negociación colectiva y también la consolidación de la democracia y de la paz en Colombia. Una reforma legal, orientada hacia la realidad y efectividad de 
los derechos colectivos reconocidos en la CPC de 1991, resulta ineludible para considerar al sindicato, por fin:

[...] no sólo como un instrumento indispensable para la mejora de las condiciones de trabajo sino como expresión de la dignidad, la libertad y la esfera de autodeterminación de la persona que trabaja y un componente esencial del Estado democrático de Derecho (Rodríguez-Piñero, 2006, p. 43).

\section{Referencias}

Agut García, C. (1997). El sindicato en la empresa (secciones y delegados sindicales). Valencia: Tirant lo Blanch.

Álvarez Cuesta, H. (2006). Puntos críticos y alternativas a las elecciones sindicales y a la mayor representatividad. Granada: Comares.

Casas Baamonde, M. E. (1988). Representatividad y mayor representatividad de los sindicatos en España. ¿Un modelo en crisis? Revista Española de Derecho del Trabajo, 33, 71-86.

Cialti, P. H. (2013a). Efficacités et fonctions de la convention collective de travail: étude comparative de l'intervention légale en Espagne et en France. Recuperado de http:// roderic.uv.es/handle/10550/27850

Cialti, P. H. (2013b). El procedimiento administrativo francés de la "extensión" como mecanismo de atribución de eficacia general al convenio colectivo sectorial. Temas laborales, Revista andaluza de trabajo y bienestar social, 121, 37-61.

Colombia, Corte Constitucional. (1992). Sentencia T-597 de 1992. M. P. Ciro Angarita Barón.

Colombia, Corte Constitucional. (1994). Sentencia C-009 de 1994. M. P. Antonio Barrera Carbonell.

Colombia, Corte Constitucional. (1995). Sentencia SU-342 de 1995. M. P. Antonio Barrera Carbonell.

Colombia, Corte Constitucional. (1996a). Sentencia SU-569 de 1996. M. P. Antonio Barrera Carbonell.

Colombia, Corte Constitucional. (1996b). Sentencia C-710 de 1996. M. P. Jorge Arango Mejía.

Colombia, Corte Constitucional. (1998). Sentencia C-377 de 1998. M. P. Alejandro Martínez Caballero. 
Colombia, Corte Constitucional. (2000a). Sentencia C-161 de 2000. M. P. Alejandro Martínez Caballero.

Colombia, Corte Constitucional. (2000b). Sentencia C-567 de 2000. M. P. Alfredo Beltrán Sierra.

Colombia, Corte Constitucional. (2000c). Sentencia C-797 de 2000. M. P. Antonio Barrera Carbonell.

Colombia, Corte Constitucional. (2002). Sentencia C-201 de 2002. M. P. Jaime Araujo Rentería.

Colombia, Corte Constitucional. (2005). Sentencia C-1234 de 2005. M. P. Alfredo Beltrán Sierra.

Colombia, Corte Constitucional. (2007). Sentencia C-280 de 2007. M. P. Humberto Antonio Sierra Porto.

Colombia, Corte Constitucional. (2008a). Sentencia C-063 de 2008. M. P. Clara Inés Vargas Hernández.

Colombia, Corte Constitucional. (2008b). Sentencia C-466 de 2008. M. P. Jaime Araujo Rentería.

Colombia, Corte Constitucional. (2008c). Sentencia C-668 de 2008. M. P. Mauricio González Cuervo.

Colombia, Corte Suprema de Justicia, Sala Laboral. (1994). Sentencia del 28 de noviembre de 1994. Rad. 6962. M. P. José Roberto Herrera Vergara.

Colombia, Corte Suprema de Justicia, Sala Laboral. (2004). Sentencia del 11 de agosto de 2004. Rad. 22396. M. P. Camilo Humberto Tarquino Gallego.

Colombia, Corte Suprema de Justicia, Sala Laboral. (2008). Sentencia del 29 de abril de 2008. Rad. 33988. M. P. Luis Javier Osorio López y Camilo Humberto Tarquino Gallego.

Colombia, Corte Suprema de Justicia, Sala Laboral. (2009). Sentencia del 3 de junio de 2009. Rad. 40428. M. P. Luis Javier Osorio López.

Colombia, Presidencia de la República. (2009). Decreto 535, febrero 24 de 2009, por el cual se reglamenta el artículo $416 \mathrm{del}$ Código Sustantivo del Trabajo.

Colombia, Presidencia de la República. (2012). Decreto 1092, mayo 24 de 2012, por medio del cual se reglamentan los artículos 7 y 8 de la Ley 411 de 1997 en lo relativo a los procedimientos de negociación y solución de controversias con las organizaciones de empleados públicos.

Colombia, Presidencia de la República. (2014a). Decreto 089, enero 20 de 2014.

Colombia, Presidencia de la República. (2014b). Decreto 160, febrero 5 de 2014.

Correa Montoya, G., Malagón Díaz, L. P., Díaz, A. M., Sanjuán, L., Sanín Vásquez, J.L. y Herrera, E. F. (2009). No es muda la muerte: informe de violaciones a la vida, la libertad e integridad de las y los sindicalistas en Colombia durante el 2008 y 
situación de impunidad de las violaciones en el periodo 1986-2009. Recuperado de http://www.ens.org.co/index.htm

Escuela Nacional Sindical. (2013). Sistema de información laboral y sindical. Reporte a diciembre de 2013. Recuperado de http://www.ens.org.co/index.shtml?s=c\&m=a

España. (1978). Constitución Política. Recuperado de www.congreso.es/docu/constituciones/1978/1978_cd.pdf

España. (2015). Estatuto de los Trabajadores. Recuperado de https://www.boe.es/ buscar/pdf/1995/BOE-A-1995-7730-consolidado.pdf

García Murcia, J. (1987). Organizaciones sindicales y empresariales más representativas. Madrid: Ministerio de Trabajo y Seguridad Social.

Gernigon, B., Odero, A. y Guido, H. (2000). Principios de la OIT sobre la negociación colectiva. Revista Internacional del Trabajo, 119(1), 37-59.

Goerlich Peset, J. M. y García Rubio, M. A. (2006). Fundamento y naturaleza de los convenios extraestatutarios. En F. Pérez de los Cobos y J. M. Goerlich (coords.), El régimen jurídico de la negociación colectiva en España. Estudios en homenaje al profesor Sala Franco (p. 578-608). Valencia: Tirant lo Blanch.

Guerrero Figueroa, G. (2011). Derecho colectivo del trabajo. 11 ed. Bogotá: Leyer.

Ministerio de Trabajo. (2012). Indicadores del mercado laboral. Población económicamente activa (PEA) y tasa global de participación (TGP). Recuperado de http:// www.mintrabajo.gov.co/empleo/indicadores-del-mercado-laboral.html

Molina, C. E. (2005). Las normas internacionales del trabajo y su efectividad en el Derecho colombiano. Bogotá: Temis.

Morin, M. L. (1988). Des titulaires du droit à la négociation collective. Droit Social, 1, 20-38.

Morin, M. L. (1993). Le dualisme de la convention collective de branche: aperçu historique. En A. Jobert, J. D. Reynaud y J. Saglio, J. (eds.), Les conventions collectives de branche: déclin ou renouveau (pp. 91-105). París: Cereq.

Navarro Nieto, F. (1987). El sindicato más representativo en la reciente historia normativa española. Relaciones Laborales, 22, 18-42.

Navarro Nieto, F. (1993). La representatividad sindical. Madrid: Ministerio de Trabajo y de la Seguridad Social.

OIT. (1948). Convenio 87 sobre la libertad sindical y la protección del derecho de sindicación. Ginebra: Autor.

OIT. (1978). Recomendación 159 sobre los procedimientos para determinar las condiciones de empleo en la administración pública Adopción: Ginebra, 64ª reunión CIT. Recuperado de http://www.ilo.org/dyn/normlex/es/f?p=NORMLEXPUB: 1 2100:0::NO:12100:P12100_INSTRUMENT_ID:312497:NO 
OIT. (1994). Libertad sindical y negociación colectiva, Conferencia Internacional del Trabajo, $81^{\circ}$ sesión, BIT.

OIT. (2006). Libertad sindical. Recopilación de decisiones y principios del Comité de libertad sindical del Consejo de Administración de la OIT. 5 ed. Ginebra: Autor.

OIT. (2007). $346^{\circ}$ informe del Comité de Libertad Sindical de la OIT. Recuperado de http://www.ilo.org/gb/GBSessions/WCMS_090084/lang--fr/index.htm

Ostau de Lafont de León, F. R. (noviembre de 2011). Presente-futuro de la negociación colectiva en Colombia. Conferencia presentada en el X Congreso Nacional de Sociología, Cali, Organizó: Universidad del Valle, Universidad Icesi y Universidad del Pacífico. Recuperado de http://observatoriosocial.udenar.edu.co/?p=488

Ostau de Lafont de León, F. R. y Niño Chavarro, L. A. (2012). Análisis de los efectos de las recomendaciones de los órganos de control de la Organización Internacional del Trabajo sobre el cumplimiento de los Convenios 87 y 98 por parte del Estado colombiano. Diálogos de saberes: investigaciones y Ciencias Sociales, 37, 49-68.

Pelissier, J., Lyon-Caen A. y Jeammaud, A. (2006). Droit du travail. 23 ed. París: Dalloz.

República de Colombia y Estados Unidos de América. (2006). Capítulo 17, Asuntos Laborales. En Acuerdo de promoción comercial entre la República de Colombia y Estados Unidos de América. Recuperado de http://www.tlc.gov.co/publicaciones.php?id=727

República de Colombia. (1951). Código Sustantivo del Trabajo. Recuperado de http:// www.secretariasenado.gov.co/senado/basedoc/codigo_sustantivo_trabajo. html

República de Colombia. (1991). Constitución Política. Recuperado de http://wsp.presidencia.gov. co/Normativa/Documents/Constitucion-Politica-Colombia.pdf República francesa, Corte de Casación, Asamblea Plenaria. (1990). RJS, No 490, 6 de abril de 1990, p. 345.

República francesa, Corte de Casación, Sala de lo Social. (1956). Droit Social, 17 de julio de 1956.

República francesa, Corte de Casación, Sala de lo Social. (1970). Bull. civ. V, No 1614 de marzo de 1970.

República francesa, Corte de Casación, Sala de lo Social. (1992). Droit Social, p. 52, rapp. Ph. WAQUET. 20 de noviembre de 1991.

República francesa, Corte de Casación, Sala de lo Social. (2001). 98-42.310 9842.369. 17 de julio de 2001. Recuperado de http://www.legifrance.gouv.fr/ affichJuriJudi.do?idTexte=JURITEXT000007045054 
Rodríguez-Piñero, M. (2006). La protección internacional de la negociación colectiva: una difícil tarea. Relaciones Laborales, 18, 43-52.

Rojas Miño, I. (1998). La eficacia jurídica de los convenios colectivos. Madrid: CES.

Roqueta Buj, R. (2007). El derecho de negociación colectiva en el Estatuto Básico del Empleado Público. Madrid: La Ley.

Rosanvallon, P. (1988). La question syndicale. París: Calmann Lévy.

Sala Franco, T. (1990). La negociación colectiva y los convenios colectivos. Bilbao: Deusto. Segrera Ayala, Y. y Torres Marenco, V. (2005). Alcances del derecho de asociación en Colombia a partir de los fallos de la Corte Constitucional colombiana con base en la influencia de los organismos internacionales sobre la materia. Revista de Derecho de la División de Ciencias Jurídicas, 23, 172-212.

Supiot, A. (1996a). Crítica del Derecho del Trabajo. Madrid: MTAS.

Supiot, A. (1996b). La loi dévorée par la convention. En P. Gérard, F. Ost, F. y M. van de Kerchove (eds.), Droit négocié, droit imposé? (pp. 631-648). Bruselas: Publications de Facultés Universitaires St Louis.

Ugarte Cataldo, J. L. (2014). Derecho del Trabajo: invención, teoría y crítica. Santiago: Thomson Reuters \& Legal publishing.

Valdés Dal-Ré, F. (1988). Representación y representatividad sindicales en España. Relaciones Laborales: Revista crítica de teoría y práctica, (14-15), 138-156.

Valdés Dal-Ré, F. (1990). El paradigma legal en la negociación colectiva. Relaciones Laborales: Revista crítica de teoría y práctica, (1), 268-276.

Valdés Dal-Ré, F. (1997). La legislación laboral negociada. Revista del Ministerio de Trabajo y Asuntos Sociales, 3, 171-184.

Verdier, J. M. (1987). Syndicats et droit syndical. Traité de droit du travail. 2 ed. París: Dalloz.

Verdier, J. M. (1991). Sur la relation entre représentation et représentativité syndicales. Droit Social, 1, 5-18.

Villegas Arbeláez, J. (2014). Negociación colectiva y sindicatos de empleados públicos. 6 ed. Bogotá: Universidad Externado de Colombia.

Yannakourou, S. (1995). L'Etat, l'autonomie collective et le travailleur. París: LGDJ. Zúñiga Romero, M. (2012). El declive del sindicalismo en Colombia y sus consecuencias frente al conflicto colectivo. Revista de Derecho, Universidad del Norte, Edición especial, 189-213. 
